\title{
STRUCTURAL ANALYSIS OF CYLINDRICAL SHAPED COMPOSITE AND TRADITIONAL NON COMPOSITE MATERIAL
}

\author{
Prof. M.M.Mirza \\ Department of Mechanical Design Engineering, \\ RIT, Islampur, Maharashtra, India \\ Rajat Rajaram Patil \\ Department of Mechanical Design Engineering, \\ RIT, Islampur, Maharashtra, India
}

\begin{abstract}
So far, structural analysis of square shaped composite material had carried out. There was untouched area of circular shaped composite material. We had carried out finite element analysis of circular shaped GFRP composite material and regular non composite (steel) material. finite element analysis results are compared with each other. We have checked feasibility of composite material over non composite material.
\end{abstract}

\section{Keywords-Composite material, GFRP}

\section{INTRODUCTION}

Composite material is nothing but combination of two or more material to achieve result as improved property material. modern era is adopting composite material products instead of traditional material. Properties such as high strength to weight ratio, ability to bring tailor made properties, good electrical and thermal properties make composite material ideal than traditional material. Composite materials are widely taking as substitute over other material because of their low weight, corrosion resistance, high fatigue strength property. Composite materials are classified as particulate composite, flake composite, fiber composite, laminated composite, filled composite. Here we are interested in laminated composites.

Input average characteristic analysis of material is essential and dominant part Such characteristic can be predicted on the basis of constituent arrangement. conventional isotropic material consist two elastic constant and two strength parameters.

Metal matrix composites are preferable over monolithic metals. Reason behind it is high strength and high modulus. High service temperature, insensitivity to moisture, higher electrical and thermal conductivity good wear resistant are essential properties of metal matrix component.

Laminated composite consist number of layers of any suitable thickness over each other. This layers are also called as lamina. Fiber orientation and material property are impacting factors in laminated composite, Length, shape, orientation, material are important factors which contribute to mechanical performance. Long and continues fibers are preferable. Unidirectional fibers gives high stiffness and strength.

Composite material playing dominating role in current era. composite material reduces weight without sacrificing performance. Structural analysis of composite material play vital role before manufacturing. So this paper gives knowledge, why composite materials are preferable over traditional non composite material.

\section{DESIGN}

a) Dimensional design

The geometry of cylinder is shown in figure. It has been approximated by hemispherical ends of $160 \mathrm{~mm}$ radius. Length of the cylindrical portion is taken as $360 \mathrm{~mm}$. The total length of the cylinder is taken as $680 \mathrm{~mm}$. Its assumed that internal pressure load of 1.2 MPa has been applied.

b) Analytical calculations for cylindrical shaped component We have ,

$\mathrm{P}=1.2 \mathrm{MPa} \quad \mathrm{D}=320 \mathrm{~mm}$

1) Cylindrical portion hoop stress $(\sigma h)$

$$
\begin{aligned}
(\sigma \mathrm{h}) & =\frac{P D}{2 t} \\
& =\frac{1.2 \times 320}{2 \times 2.5} \\
& =76.8 \mathrm{Mpa}
\end{aligned}
$$

2) Longitudinal stress $(\sigma L)$ 


$$
\begin{aligned}
\sigma \mathrm{L} & =\frac{P D}{4 t} \\
& =\frac{1.2 \times 320}{4 \times 2.5} \\
& =38.4 \mathrm{Mpa}
\end{aligned}
$$

3) Von mises stress ( $\sigma v)$

$$
\begin{aligned}
\sigma \mathrm{V} & =\sqrt{(\sigma h)(\sigma h)+(\sigma L)(\sigma L)-(\sigma h)(\sigma L)} \\
& = \\
\sqrt{(76.8)(76.8)+(38.4)(38.4)-(76.8)(38.4)} & \\
= & 66.5 \mathrm{Mpa} \\
& \text { III. FINITE ELEMENT ANALYSIS }
\end{aligned}
$$

Ansys work for longitudinal stress is as shown in fig. The maximum stress is occurring at the mid plane at which cylinder is constrained along the longitudinal direction ( $\mathrm{x}$ direction ).

\section{Properties of steel used,}

Density of steel $=7.8 \mathrm{~g} / \mathrm{cm}^{\wedge} 3$

Youngs modulus of steel $=207 \mathrm{Gpa}$

Poisons ratio of steel $=0.35$

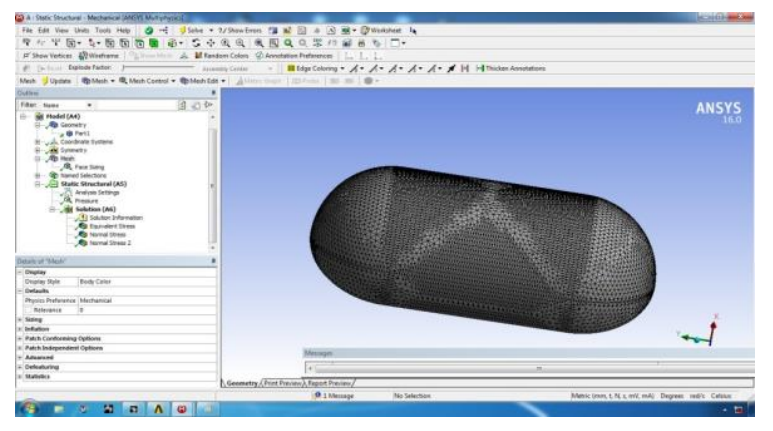

Case 1 : Cylindrical component made up of steel

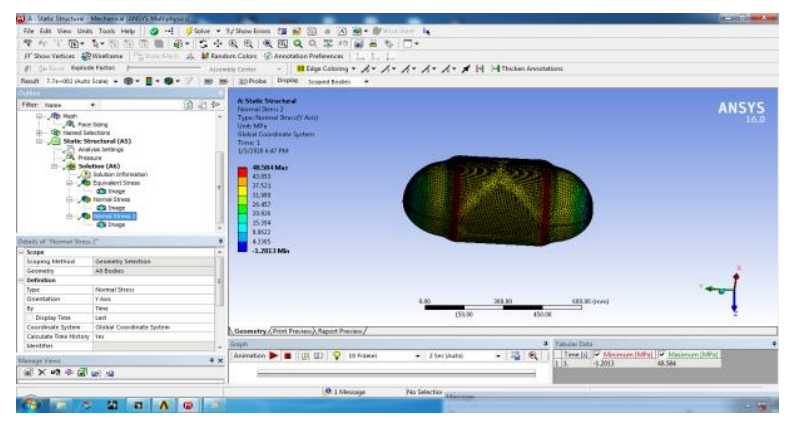

Longitudinal stress for cylindrical shaped steel component

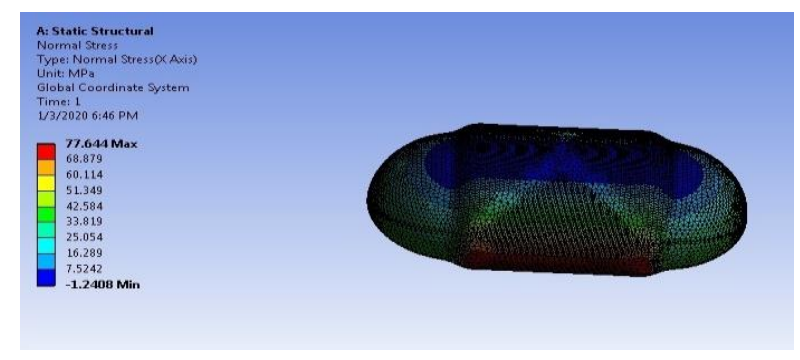

Hoop stress contour plot for steel cylinder

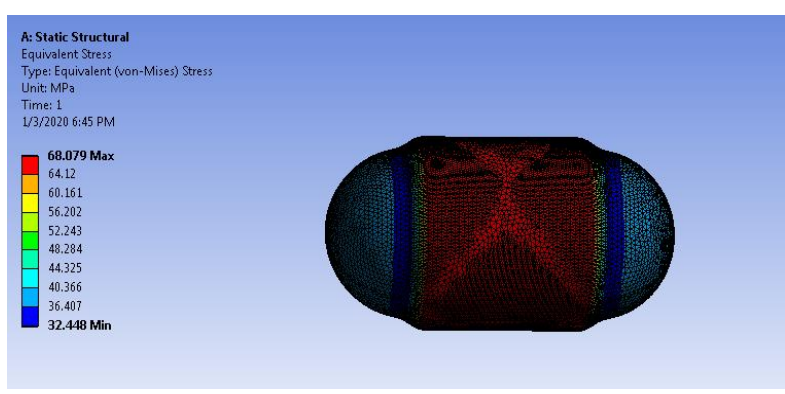

von-mises stress contour for steel cylinder

We got from Ansys work

1 Maximum longitudinal stress $=48.584 \mathrm{MPa}$

2 Maximum hoop stress $=77.664 \mathrm{MPa}$

3 Maximum von-mises stress $=68.079 \mathrm{MPa}$

Case 2 : Cylindrical component made up of GFRP The material properties are listed below.

Elastic modulus $=26 \mathrm{GPa}$

Poisons ratio $=0.28$

Density $=1.8 \mathrm{~kg} / \mathrm{mm} 3$

Yield strength $=125 \mathrm{MPa}$

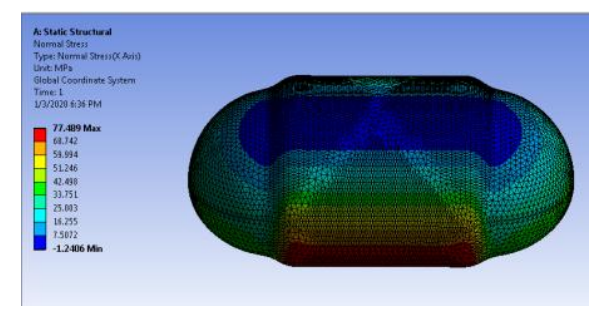

Contour plot for GFRP cylinder longitudinal stress

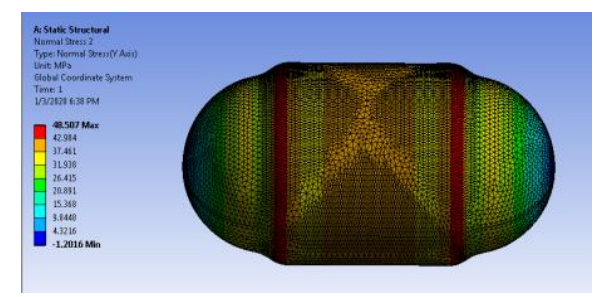

Contour plot for GFRP cylinder hoop stress 


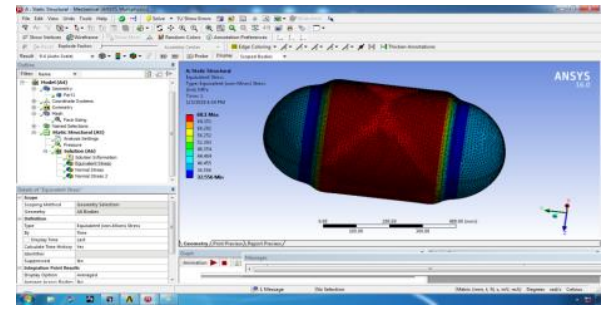

Contour plot for GFRP cylinder vonmisses stress We got following ansys results of GFRP material 1 Maximum longitudinal stress $=48.507 \mathrm{MPa}$

2 Maximum hoop stress $=77.489 \mathrm{MPa}$

3 Maximum von-mises stress $=68.1 \mathrm{MPa}$

\section{RESULTS}

After the finite element analysis we got FEA results for composite and non composite cylindrical shaped component. Results are tabulated below

[2] Kabir, M.Z (2000), "Finite element analysis of composite pressure vessels with a load sharing metallic liner". Composite Structures, 49, pp. 247-255,.

[3] Hocine A., Chapelle D., Boubakar M L, Benamar,(2007) ,'Experimental and analytical investigation of the cylindrical part of a metallic vessel reinforced by filament winding while submitted to internal pressure",International Journal of Pressure Vessels and Piping 86 649-655.

[4] JingzhongXing,PeiGeng, (2015) ,"Stress and deformation of multiple winding angle hybrid filament-wound thick cylinder under axial loading and internal and external pressure",Composite Structures 131 868-877.

[5] Stringer L.G. (1989), "Optimization of the wet layup/vacuum bag process for the fabrication of carbon fiber epoxy composites with high fiber fraction and low void content", composites. Volume 20. Number 5. pp 441451,1989

\begin{tabular}{|c|c|c|}
\hline Critetria & GFRP & STEEL \\
\hline $\begin{array}{l}\text { Max. vonmisses } \\
\text { stress in } \mathrm{MPa}\end{array}$ & 68.1 & 68.79 \\
\hline $\begin{array}{l}\text { Max. hoop stress in } \\
\mathrm{MPa}\end{array}$ & 77.489 & 77.664 \\
\hline $\begin{array}{l}\text { Max. longitudinal } \\
\text { stress in } \mathrm{MPa}\end{array}$ & 48.507 & 48.584 \\
\hline
\end{tabular}

\section{CONCLUSION}

After watching FEA results we can conclude that composite materials are preferable than non composite material. Also weight of component can be reduced by using composite material over traditional material keeping stress value within limit.

\section{REFERENCE}

[1] Quanjin m a,. Rejab m r b, Nallapaneni Manoj Kumar, (2009) ,Experimental assessment of the 3-axis filament windingmachine performance",Published by Elsevier B.V.Results in Engineering 2100017
[6] Vlot A, Gunnink JW (2001) , editors. Fiber metal laminates - an introduction. Dordrecht: Kluwer Academic; .

[7] Alderliesten RC, Homan JJ(2006) . Fatigue and damage tolerance issues of glare in aircraft structures. Int. J. Fatigue. ;28:1116-1123

[8] Botelho EC, Silva RA, Pardini LC, Rezende MC (2001). A review on the development and properties of continuous fiber/epoxy/aluminium hybrid composites for aircraft structures. Mater. Res. ;9:247-256.

[9] Borgonje B, Ypma MS (2001) . Long term behaviour of glare. Appl. Compos. Mater. ;10: 243255.

[10] Anilkumar H.C (2006) "Mechanical properties of fly ash reinforced aluminum alloy (Al6061) composites", international journal of mechanical and materials engineering 6,2011,41-45

[11] Dora siva Prasad (2011), “ mechanical properities of reinforced aluminum alloy (Al6061) composites”, international journal of mechanical and materials engineering $6,41-45$

[12] Rajendra .S .K, Ramesha .C .M (2013), "A Survey of A17075 Aluminium Metal Matrix Composites", International Journal of Science and Research" . 